\title{
Bivariate FIGARCH and Fractional Cointegration
}

\author{
Celso Brunetti \\ Department of Business Studies, The University of Edinburgh \\ Christopher L. Gilbert \\ FEWEC, Vrije Universiteit Amsterdam, QMW London and CEPR* \\ December 1999 \\ (First version October 1997)
}

\begin{abstract}
We consider the modelling of volatility on closely related markets. Univariate fractional volatility (FIGARCH) models are now standard, as are multivariate GARCH models. In this paper we adopt a combination of the two methodologies. There is as yet little consensus on the methodology for testing for fractional cointegration. The contribution of this paper is to demonstrate the feasibility of estimating and testing cointegrated bivariate FIGARCH models. We apply these methods to volatility on the NYMEX and IPE crude oil markets. We find a common order of fractional integration for the two volatility processes and confirm that they are fractionally cointegrated. An estimated error correction FIGARCH model indicates that the preponderant adjustment is of the IPE towards NYMEX.

JEL Classification: G0, C2, C3

Key words: FIGARCH, Fractional Cointegration, ECM.
\end{abstract}

\section{Introduction}

The subject of this paper is the modelling of volatility on closely related markets. This raises important questions in terms of the way the markets function

*This paper draws upon a chapter of Brunetti (1999). We thank K. Abadir, M. Sola and S. Taylor for comments on an earlier draft of this paper. We are also grateful for the comments received during seminars at Tinbergen Institute, Amsterdam, Tilburg, Pompeu Fabra where a preliminary version of this paper was presented. The first draft of this paper was also presented at the Royal Economic Society Conference (Warwick) and at the Econometric Society European Meeting (Berlin). We would like to thank the participants to those conferences for useful comments. Brunetti: Department of Business Studies, University of Edinburgh, 50 George Square, Edinburgh EH8 1JY, Scotland; email: Celso.Brunetti@ed.ac.uk, tel.: + + 44 (0) 131651 1489, fax: ++ 44 (0) 1316683053. 
and of econometric methodology. At a substantive level, we may be interested in whether an increase in volatility in one market induces additional volatility in the other, or whether, alternatively, volatility in both markets has a common origin. Methodologically, we need to acknowledge that financial market volatility is a long memory process, and this requires that we devise multivariate extensions of existing univariate methods. Finally, there is practical interest in volatility forecasting, and it is likely that there will be efficiency gains from jointly forecasting volatilities in related markets.

The GARCH class of models is now standard in modelling financial market volatility (Engle, 1982; Bollerslev, 1986; Taylor, 1986). These models attempt to account for volatility persistence, but have the feature that persistence decays relatively fast. In practice, volatility shows very long temporal dependence - i.e. the autocorrelation function decays very slowly. This motivates consideration of Fractionally Integrated GARCH (FIGARCH) models (Baillie et al, 1996) which combine high temporal dependence with parsimonious parameterization.

Our application is to the crude oil market. Two recent studies have considered fractional integrated processes for commodity returns. Barkoulas et al (1997) analyze returns on monthly averages of twenty-one commodities over the period 1960 to 1994. They find evidence for fractional integration for six of these series, three with estimated orders of integration less than unity and three greater than unity. Regime shifts may explain their results. Corazza et al (1997) analyze daily returns for six agricultural futures over the period 1981-91 and suggest that their results are consistent with fractional orders of integration. However, neither of these studies considers price volatilities where long memory is a priori more plausible. Long memory in commodity price volatilities is discussed by Brunetti (1999) - see also Wei and Leuthold (1998).

Crude oil futures are traded on the New York NYMEX market and the London IPE. ${ }^{1}$ The principal differences between the two markets relate to delivery - NYMEX contracts specify delivery on the US east coast ${ }^{2}$, while IPE contracts are settled either by Exchange for Physicals or by cash settlement against an index of cash Brent crude deals. Effectively, the NYMEX price is the price for light crude on the US eastern seaboard while the IPE price is the market price for North Sea tanker-delivered oil. Price divergences are often significant, reflecting differences in grade and differing market conditions in Europe and North America.

There are also issues of trading synchronism. The IPE starts trading at 10:02 AM GMT and stops trading at 20:13 GMT. Trading hours for NYMEX are 9:45 AM to 3:10 PM, New York time. This is an open outcry session. There is also an electronic trading system starting at 4:00 PM on Monday through Thursday, and concluding at 8:00 AM. On Sunday, the electronic trading begins at 7:00 PM - all times are New York time. For NYMEX, we analyzed settlement prices established at the end of the outcry session where liquidity concentrates.

\footnotetext{
${ }^{1}$ NYMEX is the New York Mercantile Exchange; the IPE is the International Petroleum Exchange located in London.

${ }^{2}$ Commercial buyers or sellers can exchange futures positions for physical positions of equal quantity.
} 
In principle, therefore IPE trading completely overlaps NYMEX open outcry trading. In practice, IPE evening trading may not be very liquid with the consequence that information which becomes available in the New York afternoon may not have full price impact on the IPE until the following morning.

The coexistence of NYMEX and the IPE raises the question of whether the volatility processes are similar in, or even common to, the two markets. We consider two possibilities:

- Volatility in the two markets is jointly caused by a common information arrival process. If information relates primarily to the world energy market rather than to particular sectors of that market, one would expect price movements to be similar in the two markets.

- Volatility in one market is the cause of volatility in the other. This might be the case if one market is dominant, and trading activity in that market is arbitraged across to the other. It is often supposed that NYMEX is the more important oil futures market, both because it has historical priority, and because trading NYMEX volumes are typically higher than IPE volumes.

The two hypotheses are not mutually incompatible. However, the information hypothesis implies that the volatility processes in the two markets should be similar, but does not require any direct link between the two, while the interaction view allows short term divergence but requires that volatility be linked across the markets. We will investigate the interaction hypothesis by positing that the two volatilities are (fractionally) cointegrated.

We model the structure of volatility in these two markets using the bivariate FIGARCH specification independently introduced by Teyssiere (1997) and Brunetti and Gilbert (1998). We examine two specific hypotheses:

1. Do the two volatility processes exhibit a common degree of integration?

2. Are the volatilities fractionally cointegrated?

An affirmative answer to the second question, with a cointegrating vector implying a proportionality relationship, will tend to support the interaction hypothesis. A negative answer to the second question in the context of similar or identical statistical processes will give greater weight to the informational hypothesis.

\section{The GARCH and FIGARCH Classes of Volatil- ity Models}

\subsection{Univariate Models}

The ARCH class of models, proposed by Engle (1982), models the conditional second moment of the time series $y_{t}$ by

$$
y_{t}=\mu_{t}+\varepsilon_{t}
$$




$$
\begin{aligned}
\varepsilon_{t} & =h_{t}^{\frac{1}{2}} e_{t} \\
e_{t} & \sim \operatorname{IND}(0,1) \\
h_{t} & =\omega+\alpha(L) \varepsilon_{t}^{2}
\end{aligned}
$$

where $\mu_{t}$ represents the regression function for the conditional mean, $\alpha(L)$ is a lag polynomial of order $q$ and $L$ is the lag operator. In the ARCH model the conditional variance, $h_{t}$, is a function of the information set available at time $t-1$. The functional form for the conditional variance equation specified by Engle (1982) incorporates only past squared error terms. Bollerslev (1986) enlarged the information set by inclusion of lagged conditional variances and proposed the Generalized ARCH (GARCH) model. This involves generalizing equation (4) to

$$
(1-\beta(L)) h_{t}=\omega+\alpha(L) \varepsilon_{t}^{2}
$$

where $\beta(L)$ is a lag polynomial of order $p$. By defining the skedastic innovation as

$$
v_{t}=\varepsilon_{t}^{2}-h_{t}
$$

the GARCH process may be expressed as an ARMA process in $\varepsilon_{t}^{2}$ :

$$
\phi^{\#}(L) \varepsilon_{t}^{2}=\omega+(1-\beta(L)) v_{t}
$$

where $\phi^{\#}(L)=1-\beta(L)-\alpha(L)$ is of order $r=\max (p, q)$. If $\phi^{\#}(L)$ contains a unit root the GARCH process becomes an Integrated GARCH, or IGARCH (Engle and Bollerslev, 1986)

$$
\phi^{\# \#}(L)(1-L) \varepsilon_{t}^{2}=\omega+(1-\beta(L)) v_{t} .
$$

We may interpret equation (8) as the ARIMA representation of the IGARCH process.

In order to capture the long memory component in the mean, Granger and Joyeux (1980) and Hosking (1981) separately formulated the Fractionally Integrated ARMA process or ARFIMA

$$
\varphi(L)(1-L)^{d}\left(y_{t}-\mu\right)=\vartheta(L) \varepsilon_{t}
$$

where $\varphi(L)=1-\sum_{j=1}^{r} \varphi_{j} L^{j}, \vartheta(L)=1+\sum_{j=1}^{p} \vartheta_{j} L^{j}, \mu$ is the mean of $y_{t}$ and $\varepsilon_{t}$ is white noise. In the same way, Baillie, Bollerslev and Mikkelsen (1996) introduced the Fractionally Integrated GARCH (FIGARCH) model and generalized the GARCH and IGARCH specifications by replacing the difference filter $(1-L)$ in $(8)$ by the fractional filter $(1-L)^{d}$

$$
\phi(L)(1-L)^{d} \varepsilon_{t}^{2}=\omega+(1-\beta(L)) v_{t} .
$$

The FIGARCH model imposes an ARFIMA structure on $\varepsilon_{t}^{2}$ and reduces to a GARCH model when $d=0$ and to an IGARCH model when $d=1$. The conditional variance of the FIGARCH process may be written as

$$
h_{t}=\frac{\omega}{1-\beta(1)}+\lambda(L) \varepsilon_{t}^{2}
$$

where $\lambda(L)=1-\frac{\phi(L)(1-L)^{d}}{1-\beta(L)}$. 


\subsection{Multivariate Models}

The initial generalization of univariate to multivariate GARCH is due to Bollerslev, Engle and Wooldridge (1988). As in univariate GARCH, the conditional variance-covariance matrix of the n-dimensional error term $\varepsilon_{t}$ in the multivariate $\operatorname{GARCH}(\mathrm{p}, \mathrm{q})$ model is a function of the information set at time $t-1$. Therefore, the elements of the covariance matrix follow a vector ARMA process in the squares and cross-products of the innovations

$$
\begin{aligned}
\mathbf{y}_{t} & =\boldsymbol{\mu}_{t}+\boldsymbol{\varepsilon}_{t} \\
\varepsilon_{t} & \sim N\left(0, \mathbf{H}_{t}\right) \\
\operatorname{vech}\left(\mathbf{H}_{t}\right) & =\sum_{i=1}^{q} \mathbf{A}_{i} \operatorname{vech}\left(\varepsilon_{t-i} \varepsilon_{t-i}^{\prime}\right)+\sum_{j=1}^{p} \mathbf{B}_{j} \operatorname{vech}\left(\mathbf{H}_{t-j}\right)+\boldsymbol{\omega}
\end{aligned}
$$

where, $\mathbf{y}_{t}, \boldsymbol{\mu}_{t}, \boldsymbol{\omega}$ and $\varepsilon_{t}$ are now m-vectors, and vech denotes the column stacking operator of the lower portion of a symmetric matrix. The corresponding $\operatorname{ARMA}(r, p)$ representation is

$$
\boldsymbol{\Phi}^{\#}(L) \varepsilon_{t}^{2}=\boldsymbol{\omega}+(\mathbf{I}-\mathbf{B}(L)) \mathbf{v}_{t}
$$

where $\boldsymbol{\Phi}^{\#}(L)=\mathbf{I}-\mathbf{B}(L)-\mathbf{A}(L)$. This formulation is very general and implies a total of $(m+1)+\frac{1}{2} m(m+1)+\frac{1}{4} m^{2}(m+1)^{2}(r+p)$ parameters. Bollerslev et al (1988) suggested imposition of diagonality on the $\mathbf{A}_{i}$ and $\mathbf{B}_{j}$ matrices. This model is referred to as the Diagonal Multivariate GARCH (Engle and Kroner, 1995). In parameterizing these matrices, we require the implied variance-covariance matrices, $\mathbf{H}_{t}$, to be positive definite for all values of $\mathbf{y}_{t}$ and $\varepsilon_{t}$ in the sample space. Restricting attention to the bivariate case (i.e. $\mathrm{m}=2$ ), setting $r=p=1$ and writing the covariance $h_{12, t}=\rho\left(h_{11, t} h_{22, t}\right)^{\frac{1}{2}}$, Bollerslev (1990) developed the constant correlation bivariate $\operatorname{GARCH}(1,1)$ representation

$$
\begin{aligned}
h_{11, t} & =\alpha_{11} \varepsilon_{1, t-1}^{2}+\beta_{11} h_{11, t-1}+\omega_{1} \\
h_{22, t} & =\alpha_{22} \varepsilon_{2, t-1}^{2}+\beta_{22} h_{22, t-1}+\omega_{2} \\
h_{12, t} & =\rho\left(h_{11, t} h_{22, t}\right)^{\frac{1}{2}} .
\end{aligned}
$$

This specification is considerably more parsimonious than the diagonal specification. Positive definiteness is guaranteed provided $|\rho|<1$ and $\alpha_{j j}, \beta_{j j}$ and $\omega_{j}(j=1,2)$ are such that $h_{11, t}$ and $h_{22, t}$ are always positive. ${ }^{3}$

Brunetti and Gilbert (1998) extended the multivariate GARCH model to multivariate FIGARCH using the constant correlation parameterization. This choice is motivated by three considerations:

1. It is the most parsimonious of the available specifications;

\footnotetext{
${ }^{3}$ A general factor-based solution to the problem of ensuring positive definite variancecovariance matrices was provided by Baba, Engle, Kraft and Kroner (1989). We do not pursue this in the current paper.
} 
2. The variance-covariance matrix is positive definite under weak conditions (see below);

3. Stationarity is ensured by restrictions only on the diagonal elements of $A_{i}$ and $B_{j} \cdot{ }^{4}$

The bivariate constant correlation FIGARCH model may be represented as

$$
\begin{aligned}
h_{j j, t} & =\lambda_{j j}(L) \varepsilon_{j, t}^{2}+\frac{\omega_{j}}{1-\beta_{j j}(1)} \\
h_{12, t} & =\rho\left[h_{11, t} h_{22, t}\right]^{\frac{1}{2}}
\end{aligned}
$$

where $\lambda_{j j}=1-\frac{\left[\phi_{j j}(L)\right](1-L)^{d_{j}}}{1-\beta_{j j}(L)}$, and $\mathrm{j}=1$, 2. It follows from the results in Bollerslev and Mikkelsen (1996) that positive definiteness in the bivariate diagonal FIGARCH $(1, d, 1)$ model is ensured if $|\rho|<1, \beta_{j j}-d_{j} \leq(1 / 3)\left(2-d_{j}\right)$, and $d_{j}\left[\phi_{j j}-\frac{1}{2}\left(1-d_{j}\right)\right] \leq \beta_{j j}\left(\phi_{j j}-\beta_{j j}+d_{j}\right)$. The conditional variance defined by this process is stationary for all $0 \leq d_{j} \leq 1$. In what follows, we use a general representation of equation (15), which may be represented in the ARFIMA form as

$$
\boldsymbol{\Phi}(L)\left(\begin{array}{cc}
(1-L)^{d_{1}} & 0 \\
0 & (1-L)^{d_{2}}
\end{array}\right) \varepsilon_{t}^{2}=\boldsymbol{\omega}+(\mathbf{I}-\mathbf{B}(L)) \mathbf{v}_{t}
$$

where $\boldsymbol{\Phi}_{0}=\mathbf{I}$. It is straightforward to test the hypothesis $d_{1}=d_{2}$ within this framework.

\section{Fractional Cointegration}

The notion of cointegration relates to a long run relationship between two or more time series which may move in quite different ways in the short term. The idea reflects the fact that there are long term constancies in economics, and that these latent equilibrium or law-like relationships induce reversionary behavior in the observed time series. The concept of cointegration was first introduced by Granger (1986) and Engle and Granger (1987) and was developed by Johansen (1988) and others. A series $y_{t}$ is said to be integrated of order $d$, denoted by $\mathrm{I}(d)$, if by differencing $d$ times it may be expressed as a stable and invertible ARMA process (Abadir and Taylor, 1998). Consider two series $y_{1, t} \backsim I(d)$ and $y_{2, t} \backsim I(d)$. Confining attention to linear cointegrating relationships, these series are said to be cointegrated if there exists a $\gamma_{2} \neq 0$, such that $z_{t}=$ $y_{1, t}+\gamma_{2} y_{2, t} \backsim I(d-b)$, where $b>0$. The idea of cointegration is that $z_{t}$ has a lower order of integration than its components $y_{1, t}$ and $y_{2, t}$.

Two arbitrarily chosen series $y_{1, t}$ and $y_{2, t}$ will not in general be integrated of the same order. However, if we confine attention to linear cointegrating relationships, a common order of integration is a necessary condition for cointegration (Abadir and Taylor, 1998; Robinson and Marinucci, 1998).

\footnotetext{
${ }^{4}$ This is true for all diagonal models - see Engle and Kroner (1995).
} 
It is useful to distinguish between integer and fractional cointegration. Most attention has been devoted to what Robinson and Marinucci describe as the "I $\mathrm{I}(1) / \mathrm{I}(0)$ paradigm" which sets $d=1$ and $b=1 .{ }^{5}$ Usually, testing for cointegration involves preliminary unit root tests. If the series are found to be integrated of order 1, a cointegration test is implemented. There are two main approaches to cointegration testing - the Johansen and the Engle-Granger methods, the former employing a Vector AutoRegressive (VAR) framework, and the latter a least squares-based test on the residuals from the OLS estimates of the cointegrating equation.

In certain contexts, in particular that of high frequency financial data, it appears over-restrictive to confine attention to integer-valued orders of integration - see for example Baillie and Bollerslev (1994a). Fractional cointegration analysis departs from the $\mathrm{I}(1) / \mathrm{I}(0)$ paradigm by allowing $b$, and possibly also $d$, to be fractional. The standard test for fractional cointegration follows the Engle-Granger two stage approach, although there are now either three or four distinct steps.

- Determine the orders of integration, $d_{1}$ and $d_{2}$, of the series under consideration $\left(y_{1, t}, y_{2, t}\right)$.

- Test whether $d_{1}=d_{2}$ i.e. whether $y_{1, t}$ and $y_{2, t}$ exhibit a common order of integration, $d$.

- Estimate the candidate cointegrating linear combination of the series and determine the order of integration $d^{\prime}$ of the cointegrating residuals. If $d=1$, a test of $d^{\prime}<1$ gives a test for fractional cointegration. Note that OLS estimation of the cointegrating vector is only consistent if $d>\frac{1}{2}$ (Robinson and Marinucci, 1998).

- If $d \neq 1$, a fourth step is required, testing $d^{\prime}<d$.

Cheung and Lai (1993), and Baillie and Bollerslev (1994a, 1994b) based their tests for fractional cointegration on the assumption that $d=1$. They then test for the order of integration of the linear combination of the series and found evidence of fractional cointegration. The assumption that $d=1$ may be strong. Dueker and Startz (1998, p.420) argue that "the uncertainty regarding the order of integration of the parent series can be even more important than uncertainty regarding the order of integration of the cointegrating vector when testing for cointegration". Drawing on Sowell (1989), they estimate a bivariate ARFIMA model for the US bond rate $\left(y_{1, t}\right)$ and a linear combination of the US and Canadian bond rates $\left(y_{2, t}\right)$. This methodology allows them to estimate both $d_{1}$ and the order of integration $d^{\prime}=d_{1}-b$ of the cointegrating vector. However, they do not test $d_{1}=d_{2}$, which is a necessary condition for fractional cointegration. Their procedure is therefore only valid if it is known a priori that the two series have the same order of integration.

\footnotetext{
${ }^{5}$ Both Granger (1986) and Engle and Granger (1987) mention fractional cointegration but their main focus is integer cointegration.
} 
Robinson and Marinucci (1998) propose a procedure for testing for fractional cointegration which involves all four of the steps outlined above. They estimate $d_{1}$ and $d_{2}$ semiparametrically exploiting the asymptotic theory set out in Robinson (1995a); undertake a Wald test of $d_{1}=d_{2}$; estimate the common order of integration $d$, again using Robinson (1995a); estimate the candidate cointegrating vector using what they describe as a narrow band Frequency Domain Least Squares (FDLS) estimator (see Robinson, 1995b); and finally estimate the order of integration $d^{\prime}$ of the residuals from this cointegrating vector. An important feature of the Robinson and Marinucci procedure is that it does not require that $y_{1, t}$ and $y_{2, t}$ be non-stationary, i.e. it allows $d<\frac{1}{2} \cdot{ }^{6}$ However, the Robinson and Marinucci procedure is not directly available where the variables of interest are latent.

\section{Fractional Cointegration within the Bivariate FIGARCH Model}

Fractional cointegration in the skedastic process raises additional issues. First, the skedastic process is not directly observed and so inference is indirect, typically from the squared residuals from a parametric first order process, as in (17); and second, since skedastic processes in finance are typically found to be stationary, the procedure used to estimate any cointegrating combination cannot presuppose non-stationarity.

It is an implication of Robinson and Marinucci (1998) that, within the bivariate framework defined by (17), fractional cointegration is only meaningful if $d_{1}=d_{2}=d$ (say). Suppose that this holds and that there exists a linear combination $\varepsilon_{1, t}^{2}+\gamma_{2} \varepsilon_{2, t}^{2} \backsim I(d-b)$, where $d>b>0$. Write $\gamma^{\prime}=\left(1, \gamma_{2}\right)$. Following Granger (1986), we may write an error correction representation of the FIGARCH model (17) as

$$
\boldsymbol{\Phi}^{*}(L)(1-L)^{d} \varepsilon_{t}^{2}=\boldsymbol{\omega}+(\mathbf{I}-\mathbf{B}(L)) \mathbf{v}_{t}-\left[1-(1-L)^{b}\right](1-L)^{d-b} \boldsymbol{\xi} \gamma^{\prime} \varepsilon_{t}^{2} .
$$

The lag polynomials $\boldsymbol{\Phi}^{*}(L)$ in (18) and $\boldsymbol{\Phi}(L)$ in (17) are related by

$$
\boldsymbol{\Phi}^{*}(L)=\boldsymbol{\Phi}(L)+\left[1-(1-L)^{-b}\right] \boldsymbol{\xi} \gamma^{\prime} .
$$

Since the zero order terms of the lag polynomial $\left[1-(1-L)^{-b}\right]$ are null, it will always be possible to find an infinite order polynomial $\boldsymbol{\Phi}^{*}(L)$ satisfying (19) and with $\boldsymbol{\Phi}_{0}^{*}=\mathbf{I}$ for any given vectors $\boldsymbol{\xi}$ and $\boldsymbol{\gamma}$. It follows that, in the absence of any further restrictions, model (18) is simply a reparameterization of model (17). This implies that $\boldsymbol{\Phi}^{*}, \boldsymbol{\xi}$ and $\boldsymbol{\gamma}$ are not identified in the absence of restrictions on $\boldsymbol{\Phi}^{*}(L)$. These restrictions may be in terms of either or both order and diagonality. This is the approach we follow in Section 6 below. The

\footnotetext{
${ }^{6}$ In fact, the Robinson and Marinucci procedure may be used in all three possible cases: (i) $y_{1, t}$ and $y_{2, t}$ are stationary and $z_{t}$ is stationary with "less" memory; (ii) $y_{1, t}$ and $y_{2, t}$ are non-stationary and $z_{t}$ is "less" non-stationary; (iii) $y_{1, t}$ and $y_{2, t}$ are non-stationary and $z_{t}$ is stationary.
} 
lack of identification implies that a finding of $b<d$ in (18) is insufficient as a demonstration of fractional cointegration.

In practice, the situation is even more complicated than this. Suppose the polynomial $\boldsymbol{\Phi}(L)$ is restricted to be of finite order $r$. Since the polynomial $\left[1-(1-L)^{b}\right](1-L)^{d-b} \boldsymbol{\xi} \gamma^{\prime}$ will necessarily be infinite (unless $\boldsymbol{\xi}$ and/or $\boldsymbol{\gamma}=0$ or $b=1), \boldsymbol{\Phi}^{*}(L)$ will also be infinite. Model (18) is therefore no longer a reparameterization of model (17) if $\mathbf{\Phi}^{*}(L)$ in (18) is restricted to be of finite order, as must inevitably be the case. It follows that, for finite polynomial lag lengths, the error correction model (18) and the model (17) are neither equivalent nor nested.

There is currently no clear consensus in the literature on methods for testing for fractional cointegration. Both the composite nature of the hypotheses and the lack of nesting structure suggests that it may be preferable to test for cointegration in a less model-dependent framework. Within our framework, it is natural to consider a direct test of whether the two volatility processes are fractionally cointegrated. In performing these tests, we use both squared returns and absolute returns as proxy measures of volatility. Two stage Engel-Granger-type procedures are only available if the original series are non-stationary, and this is commonly not the case for financial market volatilities. Robinson and Marinucci (1998) suggest a frequency domain regression procedure which is available even for stationary series. However, both because this system gives a range of outcomes, depending on the frequencies considered, and because the results reported by Robinson and Marinucci (1998) appear problematic (the lowest frequency estimates are uniformly preferred), we opt for a simpler procedure in which we assume a unit cointegrating vector. This makes sense on our data since it appears plausible that volatilities on two markets for related products should move uniformly together. This hypothesis also turns out to be supported by estimates of the unrestricted error correction model (18) where we tested the hypothesis $\gamma_{2}=-1$. With a known cointegrating vector, testing for fractional cointegration becomes straightforward since one can rely on standard univariate procedures applied to the cointegrating vector.

For these reasons, we propose a four stage procedure parallel to that considered in the previous section:

1. Estimation of the fractional orders $d_{1}$ and $d_{2}$ using univariate methods. We do this in two ways: (i) from univariate ARFIMA models of the squared and absolute returns; and (ii) from univariate FIGARCH models;

2. If the two skedastic processes are fractional, we test the hypothesis $d_{1}=$ $d_{2}$ within both the restricted-diagonal (15 and 16) and the unrestrictednon-diagonal (17 and 16) bivariate FIGARCH model;

3. If there is a common degree of fractional integration, we test for fractional cointegration using the ARFIMA model of the squared and absolute returns imposing a unit cointegrating vector;

4. If there is evidence for fractional cointegration, we estimate the error cor- 
rection bivariate FIGARCH model (18) again imposing a unit cointegrating vector.

\section{Data}

Crude oil has been traded on the NYMEX in New York since 1983, and on the London IPE since 1988. Figure 1 graphs estimated volatilities, measured as monthly standard deviations of daily price returns for the second delivery contract over the entire trading history to March 1999.

In the IPE's initial years when volumes were low, volatility differed to some extent across the two markets, but subsequent to the 1990-91 Gulf War period the two graphs move very closely together. Over the nineteen nineties, there has been no clear tendency for one market to be more volatile than the other. Oil price volatility has tended to be in the range of $1 \%$ to $3 \%$ per day, but this has been punctuated by two periods of very high volatility. The first high volatility period covers the thirteen months December 1985 to December 1986. This was the period in which Saudi Arabia was aggressively attempting to impose discipline on the other OPEC countries by expanding its production. The second period, which extends from August 1990 to March 1991, covers the period of Iraqi invasion of Kuwait, and the subsequent Gulf War which reestablished Kuwait sovereignty. We concentrate our attention on the sample period where the two markets were trading together (June 1988 - March 1999). We are interested in modelling volatility in closely related markets under "normal" conditions and we therefore omit the Gulf War period (1 August 1990 to 28 March 1991) from our sample. ${ }^{7}$

Figures 2 and 3 graph the autocorrelation functions for absolute returns for NYMEX and IPE respectively. Figures 2 and 3 also show the $95 \%$ confidence interval for the estimated sample autocorrelations if the process is i.i.d. Autocorrelations show strong temporal dependence and exhibit an hyperbolic rate of decay. Those features may suggest that long-range dependence of crude oil futures markets volatility may be modelled by a fractionally integrated process.

\section{Estimation Results}

\subsection{Univariate Models}

The first stage of the analysis is to check whether the volatility processes of NYMEX and IPE exhibit long memory. We first estimate a univariate $\operatorname{ARFIMA}(r, d, p) \operatorname{model}^{8}$ (equation 9) for two volatility proxies, squared returns

\footnotetext{
${ }^{7}$ Inclusion of the Gulf War period is problematic for a number of reasons: in particular, the kurtosis of the returns distribution is considerably greater over this period, and the fractional integration parameters take much higher values - see Brunetti (1999). IPE daily returns have been computed using settlement price, which is the official price established by the IPE at the close of each trading day.

${ }^{8}$ There are many ways of testing for the presence of long memory. In particular it is possible to distinguish between parametric and semi-parametric tests. We disregard the latter and
} 
and absolute returns. ${ }^{9}$ Consistency of these estimates depends on the validity of the choice of polynomial lag lengths. Using Monte Carlo analysis, Lobato (1999) has shown that estimates of long memory models are particularly sensitive to misspecification of the length of the autoregressive polynomial. Model selection tests suggest concentration on the ARFIMA $(1, d, 1)$ model, which we estimate using the exact MLE of the ARFIMA process under normality derived by Sowell (1992). ${ }^{10}$

The results are reported in columns 1 and 2 of Table 1 . The long memory parameter estimates indicate that both absolute and squared returns are long memory and stationary processes. From columns 1 and 2 of Table 1 it is also evident that, for both markets, the estimated long memory parameter is higher for absolute returns than for squared returns. The theoretical autocorrelation of the ARFIMA process for high lags may be approximated as follows $\rho_{k} \approx c k^{2 d-1}$ where $c>0$. This implies that for high lags, the higher is the value of $d$, the higher is the autocorrelation of the process. The results in Table 1, columns 1 and 2, show that absolute returns exhibit a higher autocorrelation structure than squared returns. This is in line with the findings of Taylor (1986), Ding at al (1993), Granger and Ding (1995) and Ding and Granger (1996). Granger and Ding (1995) refer to this phenomenon as the "Taylor effect".

The second stage is estimation of univariate $\operatorname{FIGARCH}(r, d, p)$ models (10) for the two volatility processes. These estimates are obtained using the QML procedure suggested by Baillie et al (1996). We report estimates with $r=p=1$. Noting that $r=\max (p, q) \geq p$, we also investigated $\operatorname{FIGARCH}(2, d, 1)$, FI$\operatorname{GARCH}(2, d, 2)$ and FIGARCH$(3, d, 1)$ models. There is no evidence, from either the NYMEX or the IPE data, that any higher order is required. ${ }^{11}$ Estimates of

consider only parametric tests because "Despite the amount of theoretical work in attempting to derive robust semiparametric estimators of long memory parameters, there is substantial evidence documenting their poor performance in terms of bias and mean squared error." Baillie (1996, p.35). This choice is supported by the consideration that ARFIMA models describe the long-run dynamic of the conditional mean in the same way in which FIGARCH class of models does that with the conditional variance.

${ }^{9}$ For an analysis of the long memory properties of absolute returns and squared returns see Taylor (1986), Ding, Granger and Engle (1993), Granger and Ding (1995).

${ }^{10}$ The ARFIMA estimates are computed in Ox using the ARFIMA package 1.0 developed by Doornik and Ooms (1999), see also Ooms and Doornik (1998). The model selection criteria we use are the AIC and the SIC, which are related to the estimated log-likelihood by

$$
A I C=-2 \ln L(\hat{k})+2 k, S I C=-2 \ln L(\hat{k})+2 \ln (N)
$$

where $k$ is the number of estimated parameters and $N$ is the number of observations used in the estimates. The SIC puts a heavier penalty on additional parameters and, therefore, "encourages" parsimonious models. When the AIC and the SIC indicated different results we opt for the more parsimonious model by using the SIC choice. The data contains two outliers (23 March 1998 and 17 December 1998) which cause estimation problems. We control for these by introducing impulse dummies (coefficients not reported). Because the outliers are common to the two markets, there is no need to include the dummies in the cointegrating ARFIMA model.

${ }^{11}$ The sufficient conditions required to ensure that the conditional variance is always positive vary according to the model specification. These restrictions were not binding in any of the estimates we undertook. 
the univariate FIGARCH $(1, d, 1)$ are given in column 3 of Table $1 .{ }^{12}$

In this paper the analysis of the fractional order of integration of the volatility process is implemented via parametric procedures (ARFIMA and FIGARCH models). The resulting estimators are efficient and consistent iff the model is correctly specified (Robinson, 1995b; Lobato, 1999). For this reason we considered several different specifications of the ARFIMA and FIGARCH models. It is important to note that regardless of the specification adopted, the estimated values for the long memory parameter, $d$, were always consistent in the sense that they did not differ significantly from each other. ${ }^{13}$

The estimates of the ARFIMA and FIGARCH models reported in columns 1-3 of Table 1 suggest a common fractional parameter $d$ in the two markets. Conditional on the validity of this hypothesis, we can use the ARFIMA methodology to tests for a unit cointegrating vector, such that the differences in the squared or absolute returns on the two markets have a lower order of integration than those implied by the estimates in columns 1 and 2. Columns 4 and 5 of Table 1 report the estimates of univariate $\operatorname{ARFIMA}(1, d, 1)$ models for the differences in respectively the squared and absolute returns from the NYMEX and IPE markets. The order of integration of the differences in the absolute returns on the two markets (Table 1, column 4) is marginally significant and is less than those of the original series reported in column 1 . The estimate of $d$ for the linear combination of squared returns, assuming a unit cointegrating vector, is not significantly different from zero (Table 1, last column) implying that the linear combination of squared returns is $\mathrm{I}(0)$. On this basis we conclude that the NYMEX and IPE volatility processes are indeed cointegrated.

The estimates reported in Table 1 all relate to the sample which excludes the Gulf War conflict. We also estimated the $\operatorname{FIGARCH}(1, d, 1)$ models over the entire samples of available data but including a shift dummy variable for the Gulf War period in the skedastic function (results not reported). Over this extended sample, the estimates of the long memory parameter $d$ are very sensitive to the inclusion or non-inclusion of this dummy. This accords with the results reported by Lamoureux and Lastrapes (1990) who argue that estimates of the parameters of GARCH models are not robust in the presence of structural shifts.

\subsection{Bivariate Models}

The estimates of the FIGARCH models suggest a common fractional parameter $d$ in the two markets. To test this hypothesis, we need to move to a bivariate framework. The standard procedure in estimating bivariate GARCH models has

\footnotetext{
${ }^{12}$ The QML standard errors reported in column 3 of Table 1 are robust against nonnormality. We also estimated the univariate models assuming the errors follow a $t$ distribution - estimated standard errors are very similar. The two outliers contained in the data did not affect the FIGARCH estimates. Therefore, the results reported in Tables 1 and 2 refer to FIGARCH models which do not include impulse dummies.

${ }^{13}$ For example, for the several ARFIMA specification we estimated for the squared returns of IPE, the value of $d$ varies between 0.23 and 0.28 .
} 


\begin{tabular}{|c|c|c|c|c|c|c|}
\hline & \multicolumn{2}{|c|}{ 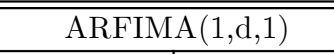 } & \multirow[t]{3}{*}{ FIGARCH $(1, \mathrm{~d}, 1)$} & \multirow{2}{*}{\multicolumn{2}{|c|}{$\begin{array}{c}\operatorname{ARFIMA}(1, \mathrm{~d}, 1) \\
z_{t}=y_{1, t}-y_{2, t}\end{array}$}} \\
\hline & & \multirow[b]{2}{*}{ Abs. Ret. } & \multirow[b]{2}{*}{ Sq. Ret. } & & & \\
\hline & & & & & Abs. Ret. & Sq. Ret. \\
\hline \multirow[b]{2}{*}{$\mathrm{N}$} & $\varphi$ & $\begin{array}{l}0.1580 \\
(0.0374)\end{array}$ & $\begin{array}{c}-0.0691 \\
(0.1242)\end{array}$ & & $\begin{array}{l}0.2361 \\
(0.0827)\end{array}$ & $\begin{array}{l}0.0541 \\
(0.1513)\end{array}$ \\
\hline & $\vartheta$ & $\begin{array}{l}-0.4434 \\
(0.0917)\end{array}$ & $\begin{array}{l}-0.1120 \\
(0.1387)\end{array}$ & & $\begin{array}{l}-0.4500 \\
(0.0977)\end{array}$ & $\begin{array}{l}-0.2056 \\
(0.1730)\end{array}$ \\
\hline $\mathrm{Y}$ & d & $\begin{array}{l}0.2752 \\
(0.0374)\end{array}$ & $\begin{array}{l}0.1626 \\
(0.0230)\end{array}$ & $\begin{array}{l}0.3469 \\
(0.0518)\end{array}$ & $\begin{array}{l}0.0798 \\
(0.0410)\end{array}$ & $\begin{array}{l}0.0445 \\
(0.0374)\end{array}$ \\
\hline $\mathrm{M}$ & $\mu$ & $\begin{array}{l}1.2486 \\
(0.1274)\end{array}$ & $\begin{array}{l}2.7285 \\
(0.2812) \\
\end{array}$ & $\begin{array}{l}0.0119 \\
(0.0295)\end{array}$ & & \\
\hline $\mathrm{E}$ & $\omega$ & & & $\begin{array}{l}0.2082 \\
(0.0829)\end{array}$ & & \\
\hline \multirow[t]{2}{*}{$\mathrm{X}$} & $\beta$ & & & $\begin{array}{l}0.3809 \\
(0.1145)\end{array}$ & & \\
\hline & $\phi$ & & & $\begin{array}{l}0.0403 \\
(0.0981)\end{array}$ & & \\
\hline \multirow{7}{*}{$\mathrm{E}$} & $\varphi$ & $\begin{array}{l}0.2927 \\
(0.0528)\end{array}$ & $\begin{array}{l}0.3152 \\
(0.0629)\end{array}$ & & & \\
\hline & $\vartheta$ & $\begin{array}{l}-0.5966 \\
(0.0657)\end{array}$ & $\begin{array}{l}-0.5422 \\
(0.0743)\end{array}$ & & & \\
\hline & d & $\begin{array}{l}0.3321 \\
(0.0436)\end{array}$ & $\begin{array}{l}0.2433 \\
(0.0334)\end{array}$ & $\begin{array}{l}0.4177 \\
(0.0697)\end{array}$ & & \\
\hline & $\mu$ & $\begin{array}{l}1.2000 \\
(0.1837)\end{array}$ & $\begin{array}{l}2.5505 \\
(0.4612)\end{array}$ & $\begin{array}{l}0.0345 \\
(0.0279)\end{array}$ & & \\
\hline & $\omega$ & & & $\begin{array}{l}0.1075 \\
(0.0461)\end{array}$ & & \\
\hline & $\beta$ & & & $\begin{array}{l}0.5619 \\
(0.0929)\end{array}$ & & \\
\hline & $\phi$ & & & $\begin{array}{l}0.2038 \\
(0.0767)\end{array}$ & & \\
\hline
\end{tabular}

Table 1: Univariate Estimates

Standard errors in parenthesis. 
been to impose diagonality on $\boldsymbol{\Phi}(L)$ and $\mathbf{B}(L)$ - see, for example, Bollerslev, Engle and Wooldridge (1988). Following this approach, in column 1 of Table 2 we report estimates of diagonal bivariate constant correlation FIGARCH models $(15,16)$ with $r=p=1$. Note the similarity in the estimates of the two fractional processes. In column 2 , we report estimates of the same model imposing a common degree of fractional integration. A likelihood ratio test of these estimates against those in column 1 fails to reject the hypothesis of a common order of fractional integration.

Consistency of these estimates depends on both the validity of the lag length restrictions, as in the univariate case, and of the diagonality restrictions. We checked the former by estimating constant correlation diagonal FI$\operatorname{GARCH}(2, d, 1), \operatorname{FIGARCH}(2, d, 2)$, and $\operatorname{FIGARCH}(3, \mathrm{~d}, 1)$ models. There is no evidence that higher lag lengths are required. To check the diagonality restrictions, in column 3 of Table 2 we estimated an unrestricted constant correlation FIGARCH $(1, d, 1)$ model $(17,16) .{ }^{14}$ A likelihood ratio test against the estimates in column 1 and both AIC and SIC reject diagonality. However, we fail to reject the restriction to a common order of fractional integration (Table 2, column 4). Tests of this model against alternatives with longer lag specifications always fail to reject the first order lag length restrictions.

As already stated, for both the restricted (diagonal) and the unrestricted (non-diagonal) models, we considered several specifications. The estimated long memory parameters were very similar regardless of the model specification implemented.

From Table 2 columns 3 and 4 , it is interesting to note that $\beta_{21}$ is significantly different from zero. This coefficient captures the effects of NYMEX volatility $\left(h_{11, t-1}\right)$ on IPE volatility $\left(h_{22, t}\right)$, and in this context, it is important to recall that IPE liquidity may be low in the NYMEX afternoon session. The corresponding coefficient $\beta_{12}$ linking $h_{22, t-1}$ and $h_{11, t}$ does not differ significantly from zero.

\subsection{Error Correction Models}

The estimates of the ECM-FIGARCH model (18) are reported in column 5 of Table 2, and these are to be compared with those of the unrestricted model with $d_{1}=d_{2}$, reported in column 4 . The ECM model has the higher likelihood but because the models are not nested (see section 4 above), no direct test is possible. However, both the Akaike and Schwarz criteria strongly indicate a preference of the ECM specification. The estimates of the order of integration of the parent series is 0.40 and it is significantly different from zero. The estimates of $b$ indicates that the volatility processes of the two crude oil futures markets are fractionally cointegrated. The order of integration of the linear combination of the two volatility processes is given by $d^{\prime}=d-b$ which is equal to 0.22 with a standard error of 0.06 . This implies that the linear combination of the

\footnotetext{
${ }^{14}$ The necessary conditions for positive definiteness of the variance-covariance matrix in the unrestricted FIGARCH $(1, d, 1)$ model are $|\rho|<1, \beta_{j j}-d_{j} \leq(1 / 3)\left(2-d_{j}\right), d_{j}\left[\phi_{j j}-\frac{1}{2}\left(1-d_{j}\right)\right] \leq$ $\beta_{j j}\left(\phi_{j j}-\beta_{j j}+d_{j}\right)$ and $\phi_{i j}>\beta_{i j}(i, j=1,2 ; i \neq j)$.
} 


\begin{tabular}{|c|c|c|c|c|c|c|c|}
\hline & \multicolumn{2}{|c|}{ Diagonal } & \multicolumn{2}{|c|}{ Unrestricted } & \multicolumn{2}{|c|}{ ECM } \\
\hline & & & $d_{1}=d_{2}$ & & $d_{1}=d_{2}$ & $d_{1}=d_{2}$ & $\begin{array}{l}d_{1}=d_{2} \\
\beta_{12}=0\end{array}$ \\
\hline \multirow[b]{2}{*}{$\mathrm{N}$} & $\mu_{1}$ & $\begin{array}{l}0.0040 \\
(0.0271)\end{array}$ & $\begin{array}{l}0.0039 \\
(0.0268)\end{array}$ & $\begin{array}{l}-0.0016 \\
(0.0329)\end{array}$ & $\begin{array}{l}-0.0011 \\
(0.0304)\end{array}$ & $\begin{array}{l}-0.0010 \\
(0.0263)\end{array}$ & $\begin{array}{c}-0.0020 \\
(0.0260)\end{array}$ \\
\hline & $\omega_{1}$ & $\begin{array}{l}0.1021 \\
(0.0344)\end{array}$ & $\begin{array}{l}0.0934 \\
(0.0307)\end{array}$ & $\begin{array}{l}0.1429 \\
(0.0965)\end{array}$ & $\begin{array}{l}0.1255 \\
(0.0856)\end{array}$ & $\begin{array}{l}0.0921 \\
(0.0333)\end{array}$ & $\begin{array}{l}0.0865 \\
(0.0291)\end{array}$ \\
\hline $\mathrm{Y}$ & $\beta_{11}$ & $\begin{array}{l}0.4414 \\
(0.0627)\end{array}$ & $\begin{array}{l}0.4612 \\
(0.0567)\end{array}$ & $\begin{array}{l}0.3958 \\
(0.1869)\end{array}$ & $\begin{array}{l}0.4387 \\
(0.1625)\end{array}$ & $\begin{array}{l}0.3496 \\
(0.1598)\end{array}$ & $\begin{array}{l}0.4572 \\
(0.0587)\end{array}$ \\
\hline M & $\beta_{12}$ & & & $\begin{array}{l}-0.1003 \\
(0.0950)\end{array}$ & $\begin{array}{l}-0.1125 \\
(0.0976)\end{array}$ & $\begin{array}{l}0.1008 \\
(0.1400)\end{array}$ & \\
\hline $\mathrm{E}$ & $\phi_{11}$ & $\begin{array}{l}0.1105 \\
(0.0490)\end{array}$ & $\begin{array}{l}0.1168 \\
(0.0468)\end{array}$ & $\begin{array}{l}0.1301 \\
(0.1529)\end{array}$ & $\begin{array}{l}0.1578 \\
(0.1342)\end{array}$ & $\begin{array}{l}0.1293 \\
(0.0493)\end{array}$ & $\begin{array}{l}0.1370 \\
(0.0428)\end{array}$ \\
\hline \multirow[t]{3}{*}{$\mathrm{X}$} & $\phi_{12}$ & & & $\begin{array}{l}-0.0809 \\
(0.1095)\end{array}$ & $\begin{array}{l}-0.0927 \\
(0.1132)\end{array}$ & & \\
\hline & $d_{1}$ & $\begin{array}{l}0.3515 \\
(0.0303)\end{array}$ & $\begin{array}{l}0.3654 \\
(0.0268)\end{array}$ & $\begin{array}{l}0.3233 \\
(0.0394)\end{array}$ & $\begin{array}{l}0.3383 \\
(0.0396)\end{array}$ & $\begin{array}{l}0.3966 \\
(0.0354)\end{array}$ & $\begin{array}{l}0.4025 \\
(0.0355)\end{array}$ \\
\hline & $\xi_{1}$ & & & & & $\begin{array}{l}-0.7336 \\
(0.8208)\end{array}$ & $\begin{array}{l}-0.2277 \\
(0.1244)\end{array}$ \\
\hline \multirow[b]{4}{*}{$\mathrm{P}$} & $\mu_{2}$ & $\begin{array}{l}0.0180 \\
(0.0259)\end{array}$ & $\begin{array}{l}0.0180 \\
(0.0255)\end{array}$ & $\begin{array}{l}0.0147 \\
(0.0299)\end{array}$ & $\begin{array}{l}0.0154 \\
(0.0280)\end{array}$ & $\begin{array}{l}0.0161 \\
(0.0256)\end{array}$ & $\begin{array}{l}0.0152 \\
(0.0234)\end{array}$ \\
\hline & $\omega_{2}$ & $\begin{array}{l}0.0625 \\
(0.0220)\end{array}$ & $\begin{array}{l}0.0694 \\
(0.0226)\end{array}$ & $\begin{array}{l}0.0859 \\
(0.0464)\end{array}$ & $\begin{array}{l}0.0899 \\
(0.0475)\end{array}$ & $\begin{array}{l}0.0883 \\
(0.0454)\end{array}$ & $\begin{array}{l}0.0876 \\
(0.0477)\end{array}$ \\
\hline & $\beta_{21}$ & & & $\begin{array}{l}-0.1791 \\
(0.0854)\end{array}$ & $\begin{array}{l}-0.1867 \\
(0.0829)\end{array}$ & $\begin{array}{l}-0.4585 \\
(0.2277)\end{array}$ & $\begin{array}{l}-0.5781 \\
(0.1473)\end{array}$ \\
\hline & $\beta_{22}$ & $\begin{array}{l}0.5543 \\
(0.0432)\end{array}$ & $\begin{array}{l}0.5416 \\
(0.0413)\end{array}$ & $\begin{array}{l}0.7281 \\
(0.0682)\end{array}$ & $\begin{array}{l}0.7143 \\
(0.0689)\end{array}$ & $\begin{array}{l}0.7035 \\
(0.1768)\end{array}$ & $\begin{array}{l}0.8043 \\
(0.1249)\end{array}$ \\
\hline \multirow[t]{4}{*}{$\mathrm{E}$} & $\phi_{21}$ & & & $\begin{array}{l}-0.0411 \\
(0.0984)\end{array}$ & $\begin{array}{l}-0.0549 \\
(0.0901)\end{array}$ & & \\
\hline & $\phi_{22}$ & $\begin{array}{l}0.2338 \\
(0.0337)\end{array}$ & $\begin{array}{l}0.2343 \\
(0.0346)\end{array}$ & $\begin{array}{l}0.3982 \\
(0.0746)\end{array}$ & $\begin{array}{l}0.3961 \\
(0.0749)\end{array}$ & $\begin{array}{l}0.0227 \\
(0.0868)\end{array}$ & $\begin{array}{l}0.0027 \\
(0.0739)\end{array}$ \\
\hline & $d_{2}$ & $\begin{array}{l}0.3792 \\
(0.0326)\end{array}$ & & $\begin{array}{l}0.3501 \\
(0.0432)\end{array}$ & & & \\
\hline & $\xi_{2}$ & & & & & $\begin{array}{l}4.7717 \\
(1.9312)\end{array}$ & $\begin{array}{l}5.0678 \\
(1.9133)\end{array}$ \\
\hline & $\rho$ & $\begin{array}{l}0.8551 \\
(0.0049)\end{array}$ & $\begin{array}{l}0.8550 \\
(0.0049)\end{array}$ & $\begin{array}{l}0.8631 \\
(0.0096)\end{array}$ & $\begin{array}{l}0.8625 \\
(0.0096)\end{array}$ & $\begin{array}{l}0.8677 \\
(0.0046)\end{array}$ & $\begin{array}{l}0.8680 \\
(0.0046)\end{array}$ \\
\hline & $b$ & & & & & $\begin{array}{l}0.1807 \\
(0.0728)\end{array}$ & $\begin{array}{l}0.1908 \\
(0.0723)\end{array}$ \\
\hline \multicolumn{2}{|c|}{ Loglik } & -5194.72 & -5195.07 & -5127.03 & -5127.97 & -5097.77 & -5098.02 \\
\hline \multicolumn{2}{|c|}{$\mathrm{AIC}$} & 10411.4 & 10410.1 & 10284.1 & 10283.9 & 10225.5 & 10224.04 \\
\hline \multicolumn{2}{|c|}{ SIC } & 10475.5 & 10468.4 & 10371.4 & 10365.5 & 10312.9 & 10305.56 \\
\hline
\end{tabular}

Table 2: MLE Bivariate Estimates

Standard errors in parenthesis. $\Phi^{*}(L)$ in the ECM is diagonal. 
two volatility processes is still a long memory process but exhibits an order of fractional integration lower than the two parent series $\left(d^{\prime}<d\right)$.

In the ECM-FIGARCH estimates reported in column 5 of Table 2 we imposed a unit cointegrated vector $\left(\gamma_{2}=-1\right)$. We tested this hypothesis and we fail to reject the null of $\gamma_{2}=-1$. In the ECM estimates we are also imposing diagonality on $\boldsymbol{\Phi}^{*}(L)$. We tested this restriction and we fail to reject the diagonal specification.

$\xi_{1}$ represents the speed of adjustment towards the equilibrium of the NYMEX volatility and is not statistically different from zero. By contrast, $\xi_{2}$, the speed of adjustment towards the equilibrium of the IPE volatility, is statistically important. This, together with the relative magnitude of the two estimated $\boldsymbol{\xi}$ coefficients, suggests that adjustment between the two markets primarily takes place through IPE volatility adjusting towards NYMEX volatility.

In the last column of Table 2 we test the hypothesis $\beta_{12}=0$. We fail to reject this hypothesis. ${ }^{15}$ This is consistent with the view that information which arrives during New York afternoon trading impacts on IPE prices in part during the next day's trading, as the consequence of illiquidity of London evening trading. By contrast, information which arrives during London morning trading, prior to the start of open outcry on NYMEX, will nevertheless impact NYMEX on the same day. We also test jointly $\beta_{12}=\xi_{1}=0$ (results not reported). Failure to reject this hypothesis would imply that NYMEX volatility only depends on IPE volatility through the correlation coefficient $(\rho)$. This would be consistent with the hypothesis that markets are causally independent but are impacted by a common information process. The likelihood ratio test is equal to 7.34 against a critical value of 5.99. We therefore reject $\beta_{12}=\xi_{1}=0$, implying that the markets are causally linked. The relative sizes of $\xi_{1}$ and $\xi_{2}$ (Table 2, column 6) imply that IPE volatility reacts to shocks to NYMEX volatility much more strongly than NYMEX to the IPE. In that sense, NYMEX can be said to be the dominant market, at least with regard to volatility.

\section{Conclusions}

Our objective has been to develop tractable models for volatility processes in closely related markets while simultaneously acknowledging the fractional (long memory) feature of volatility. There is as yet little consensus on the methodology for testing for fractional cointegration, in particular (as in this instance) when this relates to latent processes. The contribution of this paper has been to demonstrate the feasibility of estimating and testing cointegrated bivariate FIGARCH models, at least in the natural case in which attention is restricted to a unit cointegrating vector.

Our application has been to volatility on the two major crude oil futures markets (NYMEX and the IPE) which trade similarly defined futures contracts on closely related but non-identical underlying assets. Movements in the two volatility processes are highly correlated as must be expected with a

${ }^{15}$ The likelihhor ratio test is equal to 0.5 against a critical value of 3.84 . 
common informational feed. We find a common order of fractional integration for the two volatility processes and confirm that they are fractionally cointegrated, with weak evidence that their difference is stationary. An error correction FIGARCH model indicates that the preponderant adjustment is of the IPE towards NYMEX, in line with the conventional wisdom that NYMEX is the dominant market.

\section{References}

[1] Abadir K. M., and A. M. R., Taylor (1998), "On the Definitions of Cointegration", Mimeo.

[2] Baba, Y, Engle, R. F., Kraft, D. F., and K. F., Kroner (1989), "Multivariate Simultaneous Generalized ARCH", Discussion paper 89-57, Department of Economics, University of California, San Diego.

[3] Baillie, R. T. (1996), "Long Memory Processes and Fractional Integration in Econometrics", Journal of Econometrics, 73, 5 - 59.

[4] Baillie, R. T, and T., Bollerslev (1994a), "Cointegration, Fractional Cointegration and Exchange Rate Dynamics", Journal of Finance, 49, 737 745 .

[5] Baillie, R. T, and T., Bollerslev (1994b), "The Long Memory of Forward Premium", Journal Of International Money and Finance, 13, 565 - 571.

[6] Baillie, R. T, Bollerslev, T., and H. O., Mikkelsen (1996), "Fractionally Integrated Generalized Autoregressive Conditional Heteroskedasticity", Journal of Econometrics, 74, 3 - 30.

[7] Barkoulas, J., Labys, W. C., and J., Onochie (1997), "Fractional Dynamics in International Commodity Prices", Journal of Futures Markets, 17, 161 189.

[8] Bollerslev, T. (1986), "Generalized Autoregressive Conditional Heteroskedasticity", Journal of Econometrics, 31, 307 - 327.

[9] Bollerslev, T. (1990), "Modelling the Coherence in Short-Run Nominal Exchange Rates: a Multivariate Generalized ARCH Approach", Review of Economic Studies, 72, 498 - 505.

[10] Bollerslev, T., Engle, R. F., and J. M., Wooldridge (1988), "A CapitalAsset Pricing Model with Time-Varying Coefficients", Journal of Political Economy, 96, 116 - 131.

Bollerslev, T., and H. O. Mikkelsen (1996), "Modelling and Pricing Long Memory in Stock Market Volatility", Journal of Econometrics, 73, 151 184. 
[11] Brunetti, C. (1999), Comovement and Volatility in International Asset Markets, Ph.D. Dissertation, QMW, London.

[12] Brunetti, C., and C. L., Gilbert (1998), "A Bivariate FIGARCH Model of Crude Oil Price Volatility", Paper No 390, Department of Economics, QMW, London.

[13] Cheung, Y-W., and K. S., Lai (1993), "A Fractional Cointegration Analysis of Purchasing Power Parity", Journal of Business $\mathcal{E}$ Economic Statistics, $11,103-112$.

[14] Corazza, M., Malliaris, A. G., and C., Nardelli (1997), "Searching for Fractal Structure in Agricultural Futures Markets", Journal of Futures Markets, 17, $433-473$.

[15] Ding, Z., Granger, C. W. J., and R. E., Engle (1993), "A Long Memory Property of Stock Market Returns and a New Model", Journal of Empirical Finance, 1, 83 - 106.

[16] Ding, Z., and C. W. J., Granger (1996), "Modelling Volatility Persistence of Speculative Returns: A New Approach", Journal of Econometrics, 73, $185-215$.

[17] Doornik, J., and M., Ooms (1999), "A Package for Estimating, Forecasting and Simulating ARFIMA Models: ARFIMA Package 1.0 for Ox", Mimeo, Nuffield College, Oxford.

[18] Dueker, M., R., Startz (1998), "Maximum Likelihood Estimation of Fractional Cointegration with an Application to U.S. and Canadian Bond Rates", Journal of the American Statistical Association, 93, 420 - 426.

[19] Engle, R. F. (1982), "Autoregressive Conditional Heteroskedasticity with Estimates of the Variance of United Kingdom Inflation", Econometrica, 50, $987-1007$.

[20] Engle, R. F., and T., Bollerslev (1986), "Modelling the Persistence of Conditional Variances", Econometric Reviews, 5, 1 - 50.

[21] Engle, R. F., and C. W. J., Granger (1987), "Co-integration and Error Correction: Representation, Estimation and Testing", Econometrica, 55, $251-276$.

[22] Engle, R. F., and K. F., Kroner (1995), "Multivariate Simultaneous Generalized ARCH", Econometric Theory, 11, 122 - 150.

[23] Granger, C. W. J. (1986), "Developments in the Study of Cointegrated Economic Variables", Oxford Bulletin of Economics and Statistics, 48, 221 -238 . 
[24] Granger, C. W. J., and R., Joyeux (1980), "An Introduction to Long Memory Time series Models and Fractional Differencing", Journal of Time Series Analysis, 1, 15 - 29.

[25] Granger, C. W. J., and Z., Ding (1995), "Some Properties of Absolute Return; An Alternative Measure of Risk", Annales D'Economie et de Statistique, 40, 67 - 91.

[26] Hosking, J. R. M. (1981), "Fractional Differencing", Biometrika, 68, 165 176.

[27] Johansen, S. (1988), "Statistical Analysis of Cointegration Vectors", Journal of Economic Dynamics and Control, 12, 231 - 254.

[28] Lamoureux, C,. and W., Lastrapes (1990), "Persistence in Variance, Structural Change, and the GARCH Model", Journal of Business and Economic Statistics, 8, 225 - 235.

[29] Lobato, I. N. (1999), "A Semiparametric two Step Estimator in a Multivariate Long Memory Model", Journal of Econometrics, 90, 129 - 153.

[30] Ooms, M., and J., Doornik (1998), "Estimation, Simulation and Forecasting for fractional Autoregressive Integrated Moving Average Models", Discussion Paper, Econometric Institute, Erasmus University Rotterdam, presented at the fourth annual meeting of the Society for Computational Economics, June 1998, Cambridge, UK.

[31] Robinson, P. M. (1994), "Semiparametric Analysis of Long-Memory Time Series", The Annals of Statistics, 22, 515 - 538.

[32] Robinson, P. M. (1995a), "Log-Periodogram Regression of Time Series with Long Range Dependence", Annals of Statistics, 23, 1048 - 1072.

[33] Robinson, P. M. (1995b), "Gaussian Semiparametric Estimation of Long Range Dependence", Annals of Statistics, 23, 1630 - 1661.

[34] Robinson, P. M., and D., Marinucci (1998), "Semiparametric Frequency Domain Analysis of Fractional Cointegration", Discussion Paper N0 EM/98/348, LSE, London.

[35] Sowell, F. (1989), Maximum Likelihood Estimation of Fractionally Integrated Time Series Models, Mimeo, Carnegie-Mellon University.

[36] Taylor, S. J. (1986), Modelling Financial Time Series, Chichester, UK: Wiley.

[37] Teyssiere, G. (1997), "Modelling Exchange Rates Volatility with Multivariate Long-Memory ARCH Processes", DT-GREQAM n. 97B03, Marseille.

[38] Wei, A., and R. M., Leuthold (1998), "Long Agricultural Futures Prices: ARCH, Long Memory, or Chaos Processes?, OFOR Paper Number 98-03. 


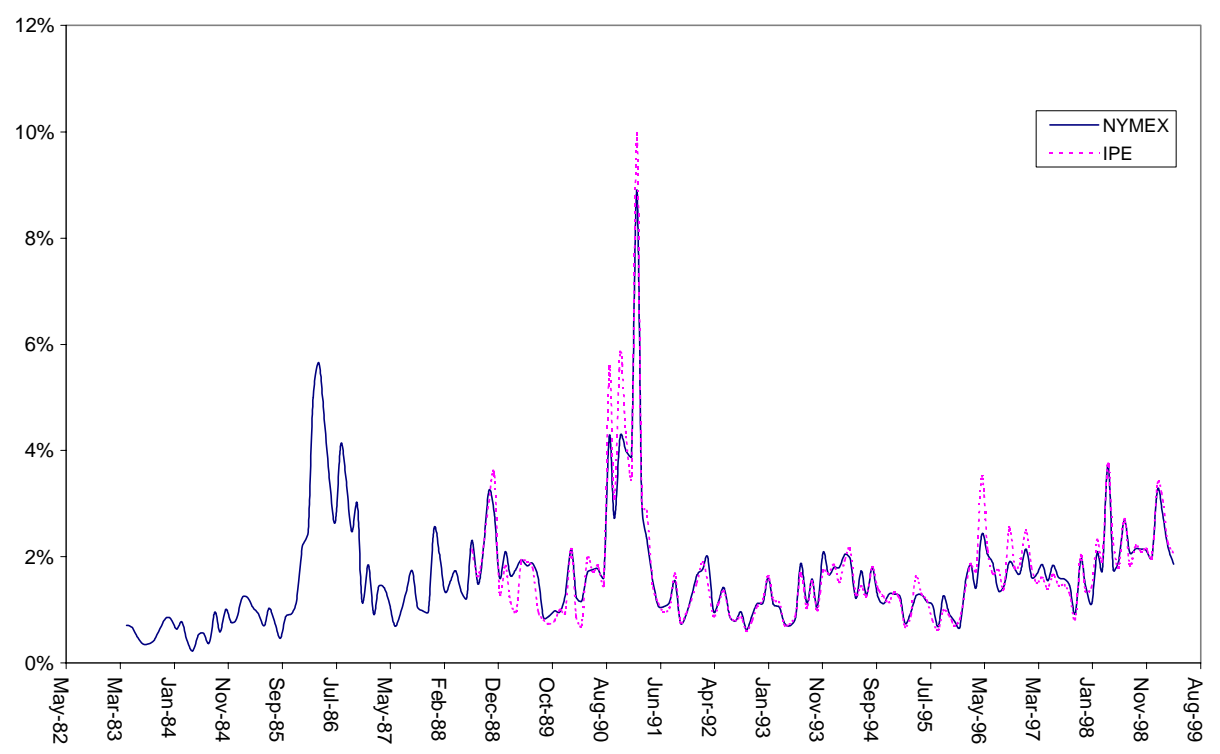

Figure 1: Monthly Crude Oil Volatilities, 1983 - 1999

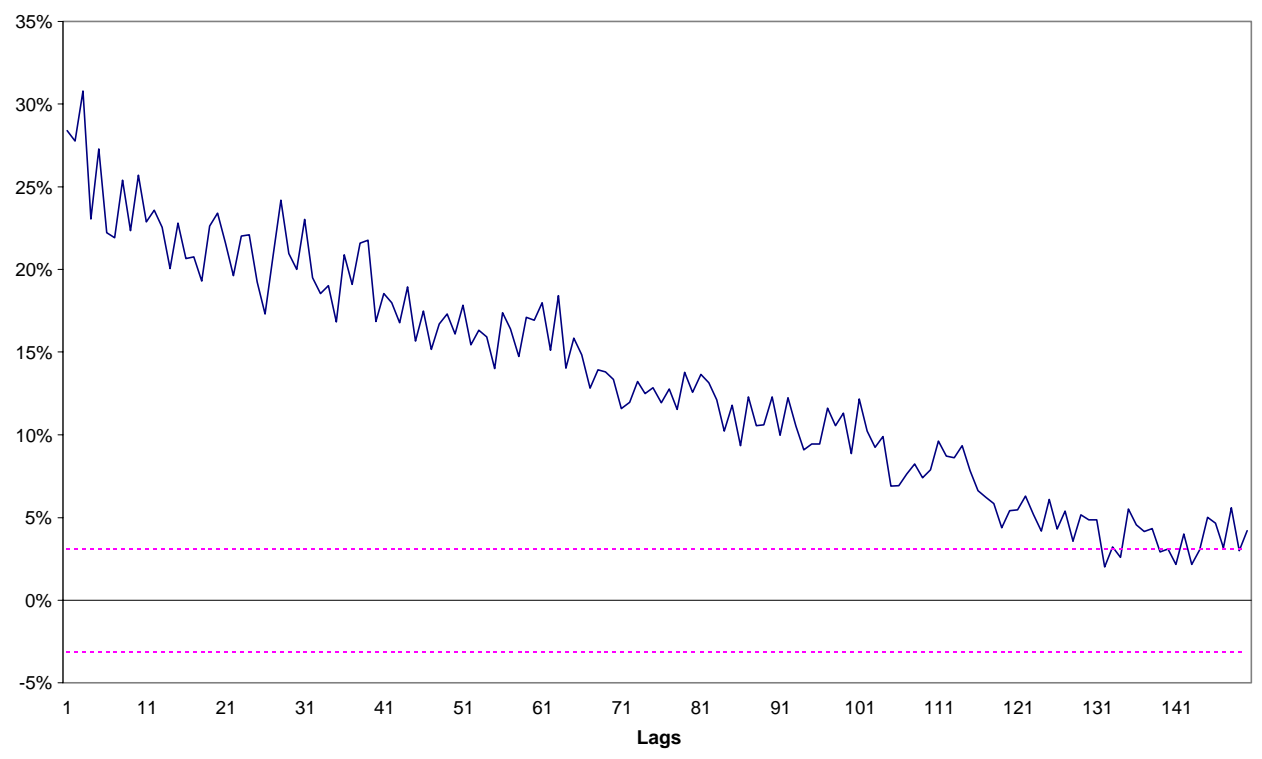

Figure 2: Autocorrelation Function, NYMEX Absolute Returns 


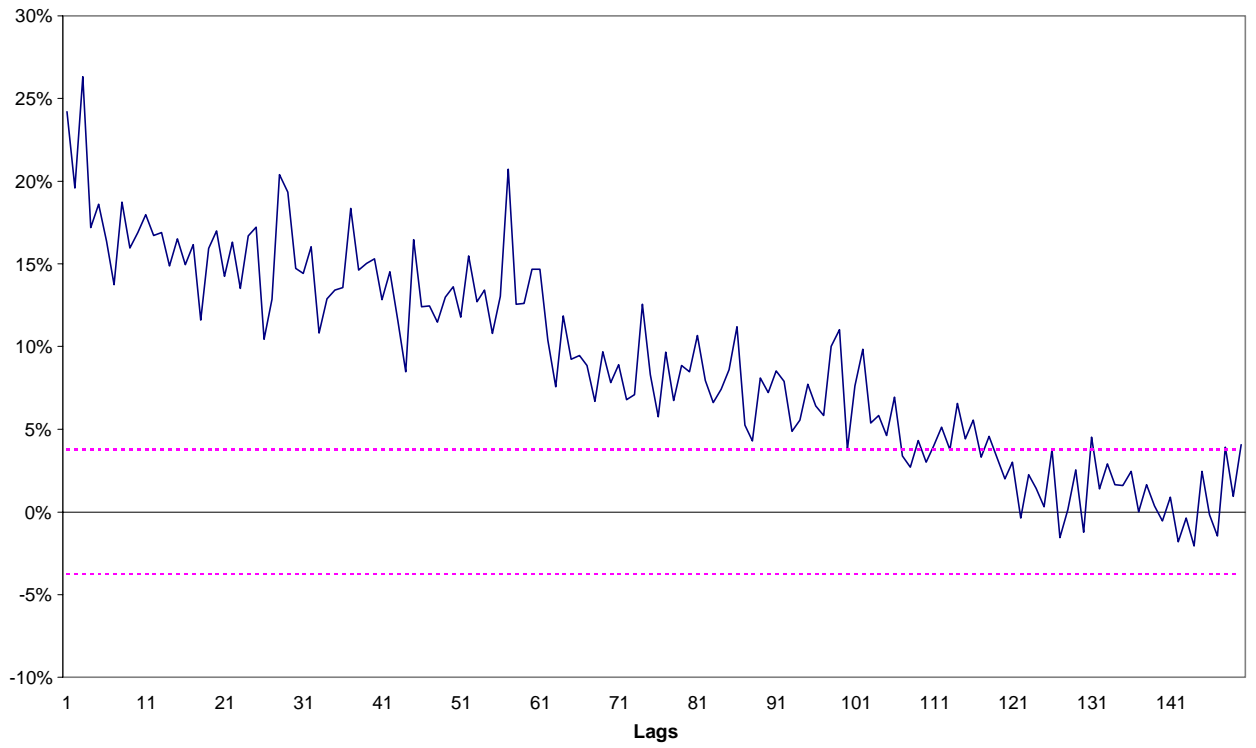

Figure 3: Autocorrelation Function, IPE Absolute Returns 